\title{
Review
}

\section{Linda Große-Segerath and Eckhard Lammert* Role of vasodilation in liver regeneration and health}

https://doi.org/10.1515/hsz-2021-0155

Received February 18, 2021; accepted April 12, 2021;

published online April 27, 2021

\begin{abstract}
Recently, we have shown that an enhanced blood flow through the liver triggers hepatocyte proliferation and thereby liver growth. In this review, we first explain the literature on hepatic blood flow and its changes after partial hepatectomy (PHx), before we present the different steps of liver regeneration that take place right after the initial hemodynamic changes induced by PHx. Those parts of the molecular mechanisms governing liver regeneration, which are directly associated with the hepatic vascular system, are subsequently reviewed. These include $\beta 1$ integrin-dependent mechanotransduction in liver sinusoidal endothelial cells (LSECs), triggering mechanically-induced activation of the vascular endothelial growth factor receptor-3 (VEGFR3) and matrix metalloproteinase-9 (MMP9) as well as release of growth-promoting angiocrine signals. Finally, we speculate how advanced age and obesity negatively affect the hepatic vasculature and thus liver regeneration and health, and we conclude our review with some recent technical progress in the clinic that employs liver perfusion. In sum, the mechano-elastic properties and alterations of the hepatic vasculature are key to better understand and influence liver health, regeneration, and disease.
\end{abstract}

*Corresponding author: Eckhard Lammert, Institute of Metabolic Physiology, Heinrich Heine University, D-40225 Düsseldorf, Germany; Institute for Vascular and Islet Cell Biology, German Diabetes Center (DDZ), Leibniz Center for Diabetes Research at Heinrich Heine University, D-40225 Düsseldorf, Germany; and German Center for Diabetes Research (DZD e.V.), Helmholtz Zentrum München, D-85764 Neuherberg, Germany, E-mail: lammert@hhu.de

Linda Große-Segerath, Institute of Metabolic Physiology, Heinrich Heine University, D-40225 Düsseldorf, Germany; Institute for Vascular and Islet Cell Biology, German Diabetes Center (DDZ), Leibniz Center for Diabetes Research at Heinrich Heine University, D-40225

Düsseldorf, Germany; and German Center for Diabetes Research (DZD e.V.), Helmholtz Zentrum München, D-85764 Neuherberg, Germany. https://orcid.org/0000-0002-9134-6984
Keywords: angiocrine signals; $\beta 1$ integrin; hepatic blood flow; liver regeneration; liver sinusoidal endothelial cells.

\section{Introduction: liver structure and blood flow}

The liver is a vital and highly vascularized organ. Its blood supply is special, since it derives from the hepatic artery and the portal vein (Figure 1A). A total of $25 \%$ of cardiac output flows through the liver. Of this, one-third flows through the hepatic artery and two-thirds through the portal vein (Lautt and Greenway 1987). The hepatic artery supplies the liver with oxygen-rich blood directly from the heart. Therefore, the pressure in the hepatic artery is comparable to the pressure in the aorta and is approximately $90 \mathrm{mmHg}$ (Eipel et al. 2010; Granger et al. 2015). In contrast, the pressure in the portal vein is much lower and ranges between 5 and $10 \mathrm{mmHg}$ (Eipel et al. 2010; Kumar et al. 2008). To reach the portal vein, the blood must first pass the gastrointestinal tract (where it takes up nutrients after food uptake), the spleen and pancreas. The hepatic artery and portal vein empty into smaller vessels - arterioles and venules - before these vessels merge into a hepatic capillary bed (Figure 1B). The capillaries of the liver are called sinusoids (Eipel et al. 2010). The pressure in sinusoids is estimated to be 1-5 mmHg and is thus even lower than in the portal vein (Boyer et al. 1977; Feng et al. 2014; Kumar et al. 2008). Blood leaves the liver with low pressure of $1-2 \mathrm{mmHg}$ via venules and the hepatic vein, and the inferior vena cava brings it back to the heart (Rocha 2012).

Consistent with the low blood pressure in the sinusoids, compared to capillary beds of most other organs, the blood flow through the hepatic sinusoids is slower. While the blood flow velocity in the cerebral capillaries of mice is about $0.93 \mathrm{~mm} / \mathrm{s}$, it is about $0.35 \mathrm{~mm} / \mathrm{s}$ in sinusoids (Fan et al. 2019; Gould et al. 2017). The low pressure and flow velocity of the blood in the sinusoids favor the exchange of gases, nutrients and waste products between the circulating blood and liver. This exchange takes place via the hepatic liver sinusoidal endothelial cells (ECs or LSECs) 


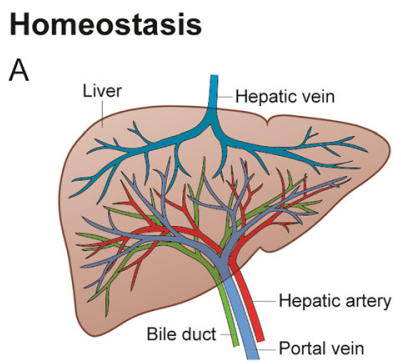

B

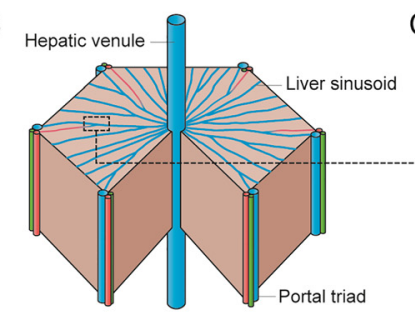

C
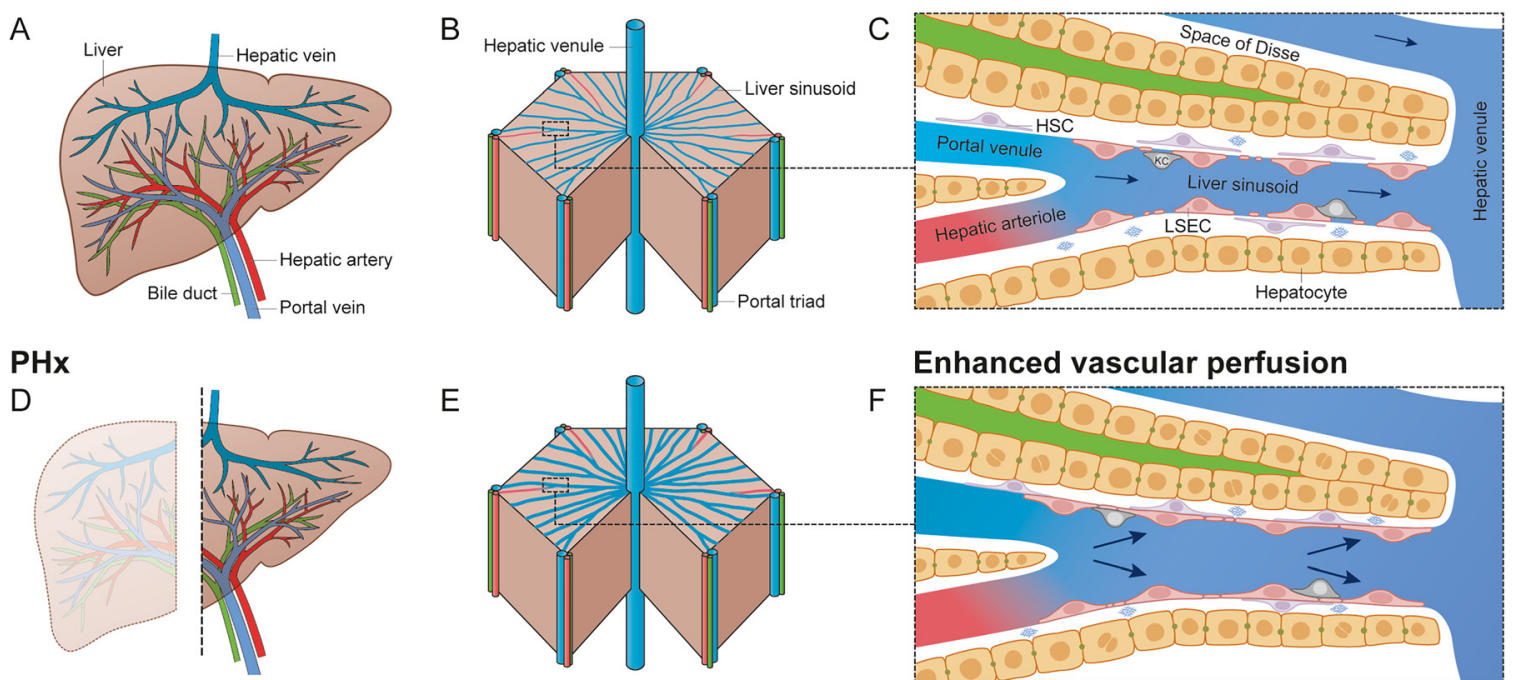

$E$

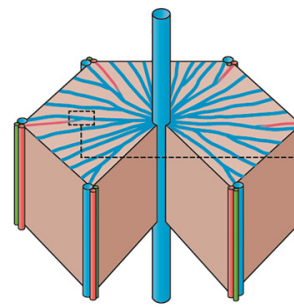

\section{Enhanced vascular perfusion}

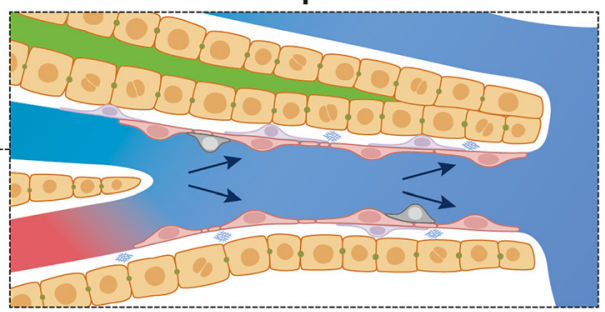

Figure 1: Blood flow in the normal liver and emerging hemodynamic changes upon partial hepatectomy.

(A-C) The liver receives a dual blood supply through the hepatic artery (red color) and portal vein (blue color). Blood flows form the portal triad through liver sinusoids and is then drained via the hepatic vein back to the heart. Arterial and venous blood mixes in the liver sinusoids, which are lined by LSECs and KCs. The latter endothelium represents a selective barrier between the blood and hepatocytes. (D-F) PHx is a procedure where up to two-thirds of the liver are surgically removed. As a result of the PHx, blood that previously flowed through the entire liver has to pass through the remaining one-third of the liver. This leads to dramatic hemodynamic changes in portal blood flow and pressure, and also to changes in the hepatic microcirculation, including a vasodilation of the sinusoidal diameter.

that separate the blood from the hepatocytes (Figure 1C). ECs are adapted to the surrounding tissue (Aird 2007a, b). For example, the capillaries in the brain are not fenestrated and tightly connected to form the blood-brain barrier (Daneman and Prat 2015). In contrast, the LSECs in the hepatic sinusoids are fenestrated, lack a distinct basement membrane, and have unique junctional complexes (Braet and Wisse 2002; Géraud et al. 2012; Sørensen et al. 2015). These features likely allow LSECs to act as a selective sieve to facilitate (and, to some extent, also regulate) the exchange of substances between blood and liver parenchyma. In addition, LSECs have a high endocytotic capacity, often mediated by stabilins, and play a role in immunity by recruiting leukocytes (Knolle and Wohlleber 2016; Li et al. 2011; Sørensen et al. 2012). Kupffer cells (KCs) are the resident macrophages in the liver and are adherent to LSECs in the sinusoidal vascular lumen. Just like LSECs, they are the first cells to come in contact with blood (Jenne and Kubes 2013). Before molecules from the blood can reach the hepatocytes after crossing the LSEC layer, they must pass an extracellular space, called the space of Disse. Measuring a size of $500-1000 \mathrm{~nm}$, the space of Disse is about one tenth of the vessel diameter of the sinusoids, but 10 times larger than the thickness of the LSEC layer (Braet and Wisse 2002; Sørensen et al. 2015). Hepatic stellate cells (HSCs), which are the pericytes of hepatic capillaries, are located within the space of Disse and maintain extracellular matrix (ECM) homeostasis in the normal liver (Häussinger and Kordes 2019). During development or acute injury, HSCs are activated to support hematopoiesis and regeneration (Sawitza et al. 2009), while in chronic inflammation of the liver, HSCs contribute to progression of liver fibrosis by excessive production of ECM proteins (Friedman 2008).

\section{Hemodynamic changes in liver regeneration}

Unlike most other organs, the liver has an advantage: it can fully regenerate or, to be more accurate, fully restore its original size (Fausto 2000; Michalopoulos and DeFrances 1997; Taub 2004). Research into the liver's ability to regenerate began with a pioneering method, the so-called 'two-thirds partial hepatectomy' (PHx), reported by Higgins and Anderson 90 years ago (Higgins and Anderson 1931). In this procedure, two-thirds of the liver is surgically removed (Figure 1D). PHx is the most common surgical resection model to study liver regeneration and is used, among others, in rats, mice and humans (Higgins and Anderson 1931; Iwatsuki and Starzl 1988; Mitchell and Willenbring 2008). In humans, PHx is used to remove diseased parts of the liver, and depending on the 
diseased pattern, removed parts of the livers can vary in size (Iwatsuki and Starzl 1988; Pack et al. 1962). A major advantage of PHx compared to chemically induced models for studying liver regeneration is that the remaining part of the liver has virtually no damage (Michalopoulos 2007).

After PHx, the liver remnant enlarges to restore the dissected two-thirds of the liver. This process is mediated by existing hepatocytes and non-parenchymal cells, such as LSECs and HSCs, and also by infiltrating endothelial progenitor cells (Michalopoulos and DeFrances 1997; Wang et al. 2012). It is remarkable that the human liver reaches its original size within few weeks. In mice and rats, this process even takes only a week (Michalopoulos 2007). The mechanism that stops liver regeneration and prevents liver overgrowth is largely unknown, but the integrin pathway and integrin-linked kinase seem to play an important role in regulating liver size (Apte et al. 2009). In addition, changes in the ECM, cytokines, such as transforming growth factor beta (TGF- $\beta$ ), and growth factors (including fibroblast growth factor (FGF) 15, and human homolog FGF19) are thought to play a role (Fausto et al. 1991; Naugler et al. 2015; Russell et al. 1988).

On average, about $5 \mathrm{~L}$ of blood are pumped through the human body every minute, of which $25 \%$ (that is, $1.25 \mathrm{~L}$ of blood) flow through the liver every minute. Therefore, when two-thirds of the liver are surgically removed by $\mathrm{PHx}$, approximately $1.25 \mathrm{~L}$ of blood must flow through the remaining one-third of the liver every minute. As a result, massive hemodynamic changes occur immediately (within seconds) after PHx (Figure 1E) (Michalopoulos 2010).

Under physiological conditions, arterial and venous blood flow and pressure can compensate each other. When portal pressure increases, the hepatic artery contracts. This phenomenon is called hepatic arterial buffer response and is also observed after PHx (Eipel et al. 2010; Lautt et al. 1990). The smaller the liver remnant in pigs, the higher the blood flow through the portal vein and the lower the blood flow through the hepatic artery (Smyrniotis et al. 2002). In rats, the measured pressure in the portal vein is also increased after PHx (Morsiani et al. 1998). It is noteworthy that too high portal pressure is not good, since if more than two-thirds of the liver are removed, the hepatic artery closes almost completely, thus resulting in liver failure (Michalopoulos 2010). Since blood from the portal vein cannot easily bypass the liver to return to the heart, it needs to flow through the liver remnant to reach the heart and get oxygenated. In contrast, blood from the hepatic artery can continue to flow through the aorta to other parts of the gastrointestinal tract and legs.
Contrast enhanced ultrasound measurements in 10 mice before and $1 \mathrm{~h}$ after $\mathrm{PHx}$ showed an increase in blood flow velocity in five mice, while the blood volume (normalized to the analyzed liver tissue) in the remaining part of the liver was doubled on average in all mice (Lorenz et al. 2018). These hemodynamic changes also affect the capillary bed of the liver (Figure 1F). While intravital fluorescence microscopy combined with an epi-illumination technique showed that diameter of sinusoids increases from 6.4 to $7.1 \mu \mathrm{m}$ in rats after PHx, liver cryosections from mice before and $1 \mathrm{~h}$ after PHx showed an even more dramatic increase in sinusoidal diameter (Dold et al. 2015; Lorenz et al. 2018).

\section{The trigger of vasodilation for liver regeneration}

Increased blood flow and pressure after PHx profoundly affect the cells of the liver (Figure 2). LSECs (as well as KCs) are the first cells that get in contact with the blood and thus with hemodynamic changes, and they respond to these changes (Augustin and Koh 2017; Ingber 2003). For example, LSECs have the ability to mediate the vascular tone by releasing vasodilators, such as nitric oxide (NO), or releasing vasoconstrictors, such as thromboxane A2 (TXA2) or endothelin-1 (ET-1) (Gracia-Sancho et al. 2019; Poisson et al. 2017; Soydemir et al. 2020). Moreover, increased shear stress can activate Krüppel-like factor 2 (KLF2), triggering the release of NO and downregulating ET-1 (Poisson et al. 2017). These vasodilators and vasoconstrictors exert their action on neighboring HSCs (Gracia-Sancho et al. 2019; Martinez-Lemus 2012), since these hepatic pericytes express a large panel of smooth muscle cell markers (e.g. SM $\alpha$-actin, SM22 $\alpha$, SM myosin heavy chain, h1-calponin and h-caldesmon (Wirz et al. 2008)), and take over the role of smooth muscle cells in sinusoids. Thus, NO secreted by LSECs reduces the contraction of HSCs, thereby promoting vasodilation in the sinusoids (Gracia-Sancho et al. 2019; Soydemir et al. 2020). Moreover, KCs also play a role in the regulation of vascular tone. For example, KCs up-regulate heme oxygenase-1 (HO-1) after PHx to promote vasodilation by production of carbon monoxide or, alternatively, release cytokines, such as tumor necrosis factor- $\alpha$ (TNF- $\alpha$ ) to promote vasoconstriction (Abshagen et al. 2007, 2008; Melgar-Lesmes and Edelman 2015).

While increased blood flow and the resulting shear stress cause LSECs to secrete vasodilators, an increased blood pressure and/or vasodilation cause circumferential stretch (Poisson et al. 2017; Urner et al. 2018), in the LSECs and associated HSCs. The latter mechanical stimulus 


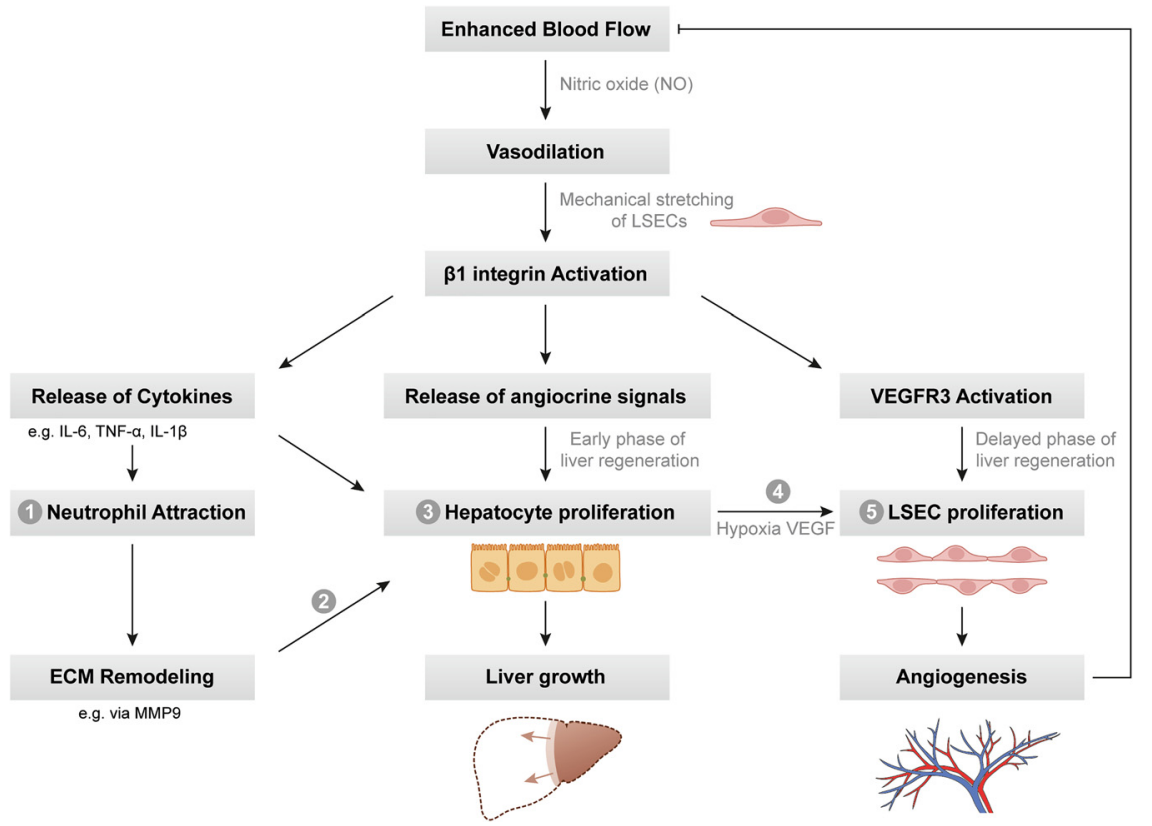

Figure 2: Hemodynamic changes after PHx promote release of angiocrine signals and trigger liver regeneration. Enhanced blood flow after PHx stimulates LSECs to release vasodilators such as NO. Vasodilation results in mechanical stretching of LSECs, and their mechanoresponsive proteins such as $\beta 1$ integrin get activated. Because $\beta 1$ integrin connects the LSECS with the vascular ECM, changes in the ECM and plasma membrane contribute to the release of growth factors and cytokines. Neutrophils migrate across LSEC layer into the space of Disse and start to further remodel the ECM. This remodeling might stimulate the further release of growth factors to promote hepatocyte proliferation. Hepatocytes receive the main stimulus for proliferation through the release of angiocrine signals such as HGF. For hepatocytes to proliferate, they require mechanically-stretched blood vessels. Due to angiogenesis, mechanical stretching is reduced, the shear stress increases in the new blood capillaries, and hepatocyte proliferation stops. Thus, liver regeneration is a highly coordinated process: hepatocytes proliferate first, followed by non-parenchymal cells. Once the vascular network is restored, there is no longer enhanced blood flow and pressure in the hepatic vasculature and liver regeneration stops.

induces LSECs to secrete growth-promoting angiocrine signals (Figure 2). In vitro experiments, in which LSECs were mechanically stretched, activated a mechanoresponsive protein, namely $\beta 1$ integrin. Additionally, experiments in mouse embryos with different heart rates and $e x$ vivo liver perfusion of adult mice with different pressures indicate that vascular perfusion activates this integrin (Lorenz et al. 2018). Notably, $\beta 1$ integrin is also required in hepatocytes themselves for proper liver regeneration, indicating a more global role of the integrin in hepatocyte proliferation (Speicher et al. 2014). Since integrins mediate cell-cell and cell-matrix contacts, integrin activation results in reorganization of ECM components, thus contributing to the release of growth factors and cytokines that are stored in the ECM or localized at the plasma membrane (Brakebusch and Fässler 2005; Kim et al. 1997). Cytokines, such as TNF- $\alpha$, interleukin-6 (IL-6) and interleukin-1 $\beta$ (IL-1ß), can be released by LSECs upon stretching and promote the recruitment of neutrophils (Figure 2, step 1) (Alvarenga et al. 2018; Schlayer et al. 1988). The latter leucocytes migrate across LSECs into the space of Disse and secrete matrix-metalloproteinases such as matrixmetalloproteinase-9 (MMP9) to remodel the ECM (Ardi et al. 2007; Li et al. 2003). MMP9-dependent proteolysis of the ECM is involved in the activation of hepatocyte growth factor (HGF) that is normally deposited in its inactive form in the ECM (Figure 2, step 2) (Kim et al. 1997; Mohammed et al. 2005).

HGF is a common 'angiocrine signal' (Rafii et al. 2016). The latter signals include, for example, cytokines, growth factors, chemokines and ECM components secreted by LSECs, and play important roles in the formation of the liver bud, liver growth and regeneration (Augustin and Koh 2017; Hoffmann et al. 2020; Kostallari and Shah 2016; Matsumoto et al. 2001; Rafii et al. 2016). Mechanical stretching of LSECs triggers the release of angiocrine HGF, IL-6, TNF- $\alpha$, and MMP9 (Lorenz et al. 2018). Although HSCs are the main source of HGF in the liver, HGF expression in LSECs markedly increases during liver regeneration in mice (Maher 1993). Homozygous deletion of HGF in mice 
results in smaller livers and is embryonic lethal (Schmidt et al. 1995), and $\beta 1$ integrin is required for the production of HGF in mouse embryos (Lorenz et al. 2018). After PHx, HGF is able to stimulate liver regeneration by promoting hepatocyte proliferation in vivo (Figure 2, step 3) (Michalopoulos and DeFrances 1997; Zhang et al. 2020). Met, which is the receptor of HGF, is also essential for liver regeneration. Elimination of Met and epidermal growth factor receptor abolishes regeneration (Michalopoulos 2007; Paranjpe et al. 2016). Angiocrine secretion of HGF is not only triggered via mechanical stimulation of LSECs, but also via vascular endothelial growth factor receptor-2 (VEGFR2)-Akt-dependent upregulation of the transcription factor Id1 or via activation of VEGFR1. After PHx, activation of VEGFR2 on LSECs stimulates expression of HGF and Wnt, and activation of VEGFR1 triggers the release of HGF, heparin-binding EGF-like growth factor (HB-EGF), connective tissue growth factor and TNF- $\alpha$ (Rafii et al. 2016). TNF- $\alpha$ levels are increased in mice after PHx, and mice lacking TNF- $\alpha$ have reduced liver regeneration (Michalopoulos 2007; Yamada et al. 1997). Similarly, IL-6-deficient mice fail to fully regenerate the liver due to reduced hepatocyte proliferation after PHx (Cressman et al. 1996). In the early phase of liver regeneration, down-regulation of angipoietin-2 (Ang2) inhibits the secretion of growthinhibiting transforming growth factor- $\beta 1$ (TGF- $\beta 1$ ) and promotes hepatocyte proliferation ( $\mathrm{Hu}$ et al. 2014). Of note, since LSECs are able to release growth-promoting angiocrine signals, their role is not only that of a passive conduit. Instead, they play an important role in organ growth and regeneration (Kostallari and Shah 2016; Lammert et al. 2003; Rafii et al. 2016). Examination of mouse livers after PHx has identified several angiocrine signals involved in liver regeneration, but to date, no angiocrine signal has been identified to induce hepatocyte proliferation on its own in vitro. In contrast, the supernatant from mechanically stretched LSECs is able to induce human hepatocyte proliferation to some extent in vitro (Lorenz et al. 2018).

Proliferation of hepatocytes is one of the first events that occurs during liver regeneration within 1-2 days, followed by proliferation of non-parenchymal cells such as LSECs and HSCs (Figure 2, step 4 and 5). LSECs begin to proliferate 2-4 days after PHx e.g. via up-regulation of Ang2 and VEGFR2 signaling (Hu et al. 2014). The secretion of VEGF-A from proliferating hepatocytes and hypoxiainduced secretion of VEGF from HSCs are important stimuli to support proliferation of LSECs (DeLeve et al. 2004; Ding et al. 2010; Dirscherl et al. 2020; Shimizu et al. 2001). In addition, VEGFR3, which is activated upon mechanical stretching of LSECs, also promotes angiogenesis (Lorenz et al. 2018; Tammela et al. 2008). Further, KCs can secrete
TNF- $\alpha$, which activates intracellular adhesion molecule- 1 (ICAM-1) on LSECs and thereby facilitates the adhesion of monocytes to promote vascular growth (Melgar-Lesmes and Edelman 2015). Hepatocyte proliferation followed by vascular expansion are processes coordinated by, for example, the hypoxia-driven Hif2a-VEGF-A axis (Figure 2, step 4) (Kron et al. 2016). Once the network of blood vessels is restored to its original size, there is no longer an enhanced blood flow and pressure in the hepatic vasculature. Similarly, just as liver regeneration is initiated by enhanced blood flow and pressure in the blood vessels, it is possible that it is terminated by restoring the pressure and flow conditions in the vascular bed to the pre-PHx state (Figure 2).

\section{Hepatic vascular changes in aging and obesity}

With increasing age and overweight, the regenerative capacity of the liver gets reduced (Beyer et al. 1991; Schmucker and Sanchez 2011; Selzner and Clavien 2000; Yang et al. 2001). A possible reason is that LSECs, HSCs and hepatocytes change morphologically with increasing age and obesity. In this context the term 'pseudocapillarization' is often used (Figure 3), meaning that LSECs become thicker and lose their fenestrae. In addition, their endocytotic activity is reduced, and molecular waste accumulates in the blood (Le Couteur et al. 2008). HSCs are often described as swollen, and this swelling might reduce the sinusoidal lumen and thus blood flow through the sinusoids (Le Couteur et al. 2008; Rohn et al. 2020). Expression of $\beta 1$ integrin on HSCs and secretion of growth factors such as HGF are also decreased during aging (Rohn et al. 2020). Moreover, the space of Disse changes with age, displaying an increased deposition of ECM proteins such as collagen type I and IV, but also decreased deposition of other ECM proteins such as laminin chains (e.g. LAMB2 and LAMC1), fibronectin, elastin and certain other collagens (Le Couteur et al. 2008; Rohn et al. 2020).

Both liver volume and blood flow were previously measured in 65 apparently healthy individuals and correlated with age. A decrease in liver volume and hepatic blood flow with increasing age was observed (Wynne et al. 1989). Interestingly, blood flow in the portal vein decreases with age, while the blood flow in the hepatic artery simultaneously increases (Zoli et al. 1999). The microcirculation is also subject to age-related changes. In 0.8 - and 27-month-old mice, the number of perfused sinusoids was shown to be reduced by up to $14 \%$ and flow by up to $35 \%$ in the older mice (Ito et al. 2007). In general, reduced blood 


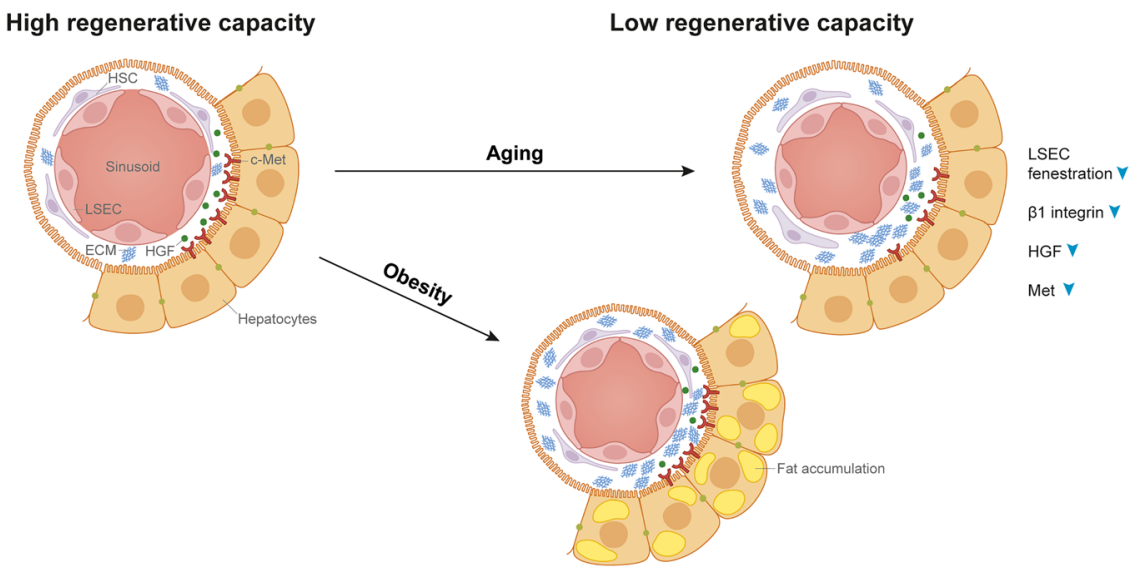

Figure 3: Vascular and cellular changes during aging and obesity impair liver regeneration. Cellular changes with age, for example, defenestration of LSECs and swelling of HSCs, reduce vasodilation in sinusoids. LSECs are thus not mechanically stretched after PHx, and the secretion of angiocrine signals that promote hepatocyte proliferation is insufficient. In obesity, vasodilation in liver sinusoids is prevented after PHx by the accumulation of fat in hepatocytes. As a result, mechanical stretching of LSECS and release of angiocrine signals are reduced. Thus, a possible scenario is presented, explaining why age and obesity are risk factors that negatively affect liver regeneration. Moreover, the LSECs encounter an increased shear stress due to the reduced vascular lumen and might even release growth-inhibiting (rather than growth-promoting) angiocrine signals.

flow can be linked to the loss of regenerative capacity in aging. There are several studies in mice and rats showing that liver regeneration after PHx is impaired in old animals (Beyer et al. 1991; Sanz et al. 1999; Schmucker and Sanchez 2011; Timchenko 2009). In both mice and humans, HGF and Met expression after PHx is lower with increasing age (Enkhbold et al. 2015; Zhu et al. 2014). In conclusion, during aging a defenestration of LSECs, swelling of HSCs, and fibrotic changes in the space of Disse, leading to impaired vasodilation of blood vessels, are noted. The lack of circumferential stretch might prevent LSECs from being mechanically stretched, thereby reducing their ability to release growthpromoting angiocrine signals that promote liver regeneration.

Similar conditions are also found in obesity. In people with fatty livers, there is a massive accumulation of fat deposits in hepatocytes, and the hepatocytes start to swell (Figure 3). The accumulation of fat in hepatocytes reduces the sinusoidal diameter by approximately $50 \%$ compared to normal liver (Farrell et al. 2008; Ijaz et al. 2003). In more severe fatty liver disease, pseudocapillarization of LSECs and collagen deposition in the space of Disse are also observed (Farrell et al. 2008; McCuskey et al. 2004). These cellular changes affect blood flow through the fatty liver. Accordingly, in fatty livers from rabbits and rats, hepatic blood flow and sinusoidal blood flow and pressure are reduced compared to control livers (Sato et al. 1986; Seifalian et al. 1999). Tissue perfusion is reduced in human liver grafts with steatosis, and while there is a correlation between blood pressure and liver volume in healthy human individuals, this correlation does not persist in patients with obesity or hepatic steatosis (Lorenz et al. 2018; Seifalian et al. 1998). While healthy livers more often recover from acute inflammation, fatty livers do not. For example, liver regeneration after PHx is impaired in homozygous 'Zucker' rats that develop severe obesity at eight weeks of age (Selzner and Clavien 2000), and mice fed a high-fat diet encounter delayed recovery of liver mass or even acute liver failure after PHx (DeAngelis et al. 2005; Valdecantos et al. 2017; Zimmers et al. 2017). In addition, obese mice with fatty livers have impaired liver regeneration after PHx despite increased levels of cytokines such as IL-6 and TNF- $\alpha$ (Yang et al. 2001). Due to the massive accumulation of fat in the liver (Figure 3), blood flow in the liver remnant is unlikely to be able to increase to a substantial extent, the sinusoidal lumen cannot dilate, LSECs do not get mechanically stretched (but encounter increased shear stress instead), and thus no growth-promoting signals are released. As a possible result, liver regeneration is blocked.

\section{Clinical applications of hepatic blood flow manipulation}

If an enhanced blood flow initiates liver regeneration, the question is whether there are applications in the clinic that take advantage. 
Liver tumors, for example, can be treated with portal vein embolization (PVE) or a method called 'associating liver partition and portal vein ligation for staged hepatectomy', short ALPPS (Knoefel et al. 2013; Lehwald-Tywuschik et al. 2020; May and Madoff 2012; Schlitt et al. 2017; Shindoh et al. 2013). Both methods are likely based on the blood flow through the liver as well as the regenerative capacity of the liver to make an inoperable liver tumor resectable (Knoefel et al. 2013; Lang et al. 2014; Schnitzbauer et al. 2012). At least $30 \%$ of the liver must remain in the body for sufficient liver regeneration (Guglielmi et al. 2012). In PVE, the blood supply of the portal vein to the diseased part of the liver is partially occluded, as to increase the blood flow in the healthy part of the liver (May and Madoff 2012; Shindoh et al. 2013). Growth-promoting angiocrine signals are likely released to make the healthy part of the liver regenerate. Thus, an adequate postoperative residual liver volume of $>30 \%$ is achieved. ALPPS combines PVE with 'in-situ split' of the liver (LehwaldTywuschik et al. 2020). In this case, portal vein inflow and intrahepatic portosystemic venous shunt are interrupted to disconnect the 'healthy' or less cancerous part of the liver from the more cancerous part. Blood flow is enhanced in the healthy part, and the liver grows. After approximately one week, $>30 \%$ of the healthy liver tissue has developed, and a second surgery is performed to separate the previously occluded part of the liver (and to resect possible metastases in the newly grown part) (Knoefel et al. 2013; Lehwald-Tywuschik et al. 2020).

Recently, a new technology that takes advantage of the liver's blood flow aims to overcome liver donor shortage (Eshmuminov et al. 2020). If patients are lucky enough to receive a liver, the liver is usually flushed and cooled with preservation fluid and stored on ice until transplanted into the recipient. The sudden reperfusion of the liver in the recipient is normally associated with complication such as ischemia reperfusion-related injuries (Nasralla et al. 2018). However, maintaining the blood flow during the transport of the donor organ avoids such complications (Brockmann et al. 2009; Nasralla et al. 2018). Until now, livers could be kept functional outside the body only for up to $24 \mathrm{~h}$, sometimes not enough to get them to the place of transplantation; the newly developed perfusion machine circumvents this limitation and livers survive outside the body for up to one week. The perfusion machine supplies blood to the liver from both the portal vein and the hepatic artery, and also mimics core functions of the body (Eshmuminov et al. 2020). The longer preservation time also provides the opportunity to exploit the regenerative capacity of the liver. When blood flow is maintained, livers that could not be transplanted - due to poor quality - become functional again, and the degree of steatosis in fatty livers also declines to some extent (Eshmuminov et al. 2020; Jamieson et al. 2011; Mergental et al. 2020).

\section{Open questions and future directions}

Enhanced blood flow sensed via sinusoidal mechanotransduction triggers secretion of angiocrine signals and contributes to liver regeneration by promoting hepatocyte proliferation. From the perspective of tissue engineering, the question is raised why there is no angiocrine signal that on its own is sufficient to simulate human hepatocyte proliferation efficiently in vitro? Notably, hepatocytes are not easy to culture in vitro and also cannot be expanded well due to low proliferation rates (Garnier et al. 2018; Hu and Li 2015; $\mathrm{Hu}$ et al. 2018; Runge et al. 2000). Therefore, novel, unidentified mechanically-induced growth-promoting angiocrine signals might exist and still need to be identified.

Another question arises in relation to the new perfusion machine for preserving liver function (Eshmuminov et al. 2020). Is it possible to overcome the shortage of transplantable livers with this technology? For example, by dividing the graft into several parts, each connected to a perfusion machine in order to grow several transplantable liver grafts? In this way, at least up to three transplantable livers could be generated from just one liver graft (if this technology further develops), and patients who are urgently waiting for a graft could be helped.

Author contributions: All the authors have accepted responsibility for the entire content of this submitted manuscript and approved submission.

Research funding: This project was supported and funded by the Deutsche Forschungsgemeinschaft (DFG) through the SFB 974 ("Communication and System Relevance in Liver Damage and Regeneration"), and the Federal Ministry of Health, the Ministry of Culture and Science of North Rhine-Westphalia and the German Center for Diabetes Research (DZD e.V.). We thank Y. Koh for schematic illustrations.

Conflict of interest statement: The authors declare no conflicts of interest regarding this article.

\section{References}

Abshagen, K., Eipel, C., Kalff, J.C., Menger, M.D., and Vollmar, B. (2007). Loss of NF-KB activation in Kupffer cell-depleted mice impairs liver regeneration after partial hepatectomy. Am. J. Physiol. Gastrointest. Liver Physiol. 292: G1570-G1577. 
Abshagen, K., Eipel, C., Kalff, J.C., Menger, M.D., and Vollmar, B. (2008). Kupffer cells are mandatory for adequate liver regeneration by mediating hyperperfusion via modulation of vasoactive proteins. Microcirculation 15: 37-47.

Aird, W.C. (2007a). Phenotypic heterogeneity of the endothelium: I. Structure, function, and mechanisms. Circ. Res. 100: 158-173.

Aird, W.C. (2007b). Phenotypic heterogeneity of the endothelium: II. Representative vascular beds. Circ. Res. 100: 174-190.

Alvarenga, D.M., Mattos, M.S., Araújo, A.M., Antunes, M.M., and Menezes, G.B. (2018). Neutrophil biology within hepatic environment. Cell Tissue Res. 371: 589-598.

Apte, U., Gkretsi, V., Bowen, W.C., Mars, W.M., Luo, J.H., Donthamsetty, S., Orr, A., Monga, S.P., Wu, C., and Michalopoulos, G.K. (2009). Enhanced liver regeneration following changes induced by hepatocyte-specific genetic ablation of integrin-linked kinase. Hepatology 50: 844-851.

Ardi, V.C., Kupriyanova, T.A., Deryugina, E.I., and Quigley, J.P. (2007). Human neutrophils uniquely release TIMP-free MMP-9 to provide a potent catalytic stimulator of angiogenesis. Proc. Natl. Acad. Sci. U.S.A. 104: 20262-7.

Augustin, H.G. and Koh, G.Y. (2017). Organotypic vasculature: from descriptive heterogeneity to functional pathophysiology. Science 357: eaal2379.

Beyer, H.S., Sherman, R., and Zieve, L. (1991). Aging is associated with reduced liver regeneration and diminished thymidine kinase mRNA content and enzyme activity in the rat. J. Lab. Clin. Med. 117: 101-108.

Boyer, T.D., Triger, D.R., Horisawa, M., Redeker, A.G., and Reynolds, T.B. (1977). Direct transhepatic measurement of portal vein pressure using a thin needle. Comparison with wedged hepatic vein pressure. Gastroenterology 72: 584-589.

Braet, F., and Wisse, E. (2002). Structural and functional aspects of liver sinusoidal endothelial cell fenestrae: a review. Comp. Hepatol. 1: 1.

Brakebusch, C., and Fässler, R. (2005). $\beta 1$ Integrin function in vivo: adhesion, migration and more. Cancer Metastasis Rev. 24: 403-411.

Brockmann, J., Reddy, S., Coussios, C., Pigott, D., Guirriero, D., Hughes, D., Morovat, A., Roy, D., Winter, L., and Friend, P.J. (2009). Normothermic perfusion: a new paradigm for organ preservation. Ann. Surg. 250: 1-6.

Cressman, D.E., Greenbaum, L.E., DeAngelis, R.A., Ciliberto, G., Furth, E.E., Poli, V., and Taub, R. (1996). Liver failure and defective hepatocyte regeneration in interleukin-6-deficient mice. Science 274: 1379-1383.

Daneman, R. and Prat, A. (2015). The blood-brain barrier. Cold Spring Harb. Perspect. Biol. 7: a020412.

DeAngelis, R.A., Markiewski, M.M., Taub, R., and Lambris, J.D. (2005). A high-fat diet impairs liver regeneration in $\mathrm{C} 57 \mathrm{BL} / 6$ mice through overexpression of the NF-KB inhibitor, IKB $\alpha$. Hepatology 42: 1148-1157.

DeLeve, L.D., Wang, X., Hu, L., McCuskey, M.K., and McCuskey, R.S. (2004). Rat liver sinusoidal endothelial cell phenotype is maintained by paracrine and autocrine regulation. Am. J. Physiol. Gastrointest. Liver Physiol. 287: G757-G763.

Ding, B.S., Nolan, D.J., Butler, J.M., James, D., Babazadeh, A.O., Rosenwaks, Z., Mittal, V., Kobayashi, H., Shido, K., Lyden, D., et al (2010). Inductive angiocrine signals from sinusoidal endothelium are required for liver regeneration. Nature 468: 310-315.
Dirscherl, K., Schläpfer, M., Roth Z'graggen, B., Wenger, R.H., Booy, C., Flury-Frei, R., Fatzer, R., Aloman, C., Bartosch, B., Parent, R., et al (2020). Hypoxia sensing by hepatic stellate cells leads to VEGF-dependent angiogenesis and may contribute to accelerated liver regeneration. Sci. Rep. 10: 4392.

Dold, S., Richter, S., Kollmar, O., von Heesen, M., Scheuer, C., Laschke, M.W., Vollmar, B., Schilling, M.K., and Menger, M.D. (2015). Portal hyperperfusion after extended hepatectomy does not induce a hepatic arterial buffer response (HABR) but impairs mitochondrial redox state and hepatocellular oxygenation. PLoS One 10: e0141877.

Eipel, C., Abshagen, K., and Vollmar, B. (2010). Regulation of hepatic blood flow: the hepatic arterial buffer response revisited. World J. Gastroenterol. 16: 6046-6057.

Enkhbold, C., Morine, Y., Utsunomiya, T., Imura, S., Ikemoto, T., Arakawa, Y., Saito, Y., Yamada, S., Ishikawa, D., and Shimada, M. (2015). Dysfunction of liver regeneration in aged liver after partial hepatectomy. J. Gastroenterol. Hepatol. 30: 1217-1224.

Eshmuminov, D., Becker, D., Bautista Borrego, L., Hefti, M., Schuler, M.J., Hagedorn, C., Muller, X., Mueller, M., Onder, C., Graf, R., et al. (2020). An integrated perfusion machine preserves injured human livers for 1 week. Nat. Biotechnol. 38: 189-198.

Fan, J., Chen, C.J., Wang, Y.C., Quan, W., Wang, J.W., and Zhang, W.G. (2019). Hemodynamic changes in hepatic sinusoids of hepatic steatosis mice. World J. Gastroenterol. 25: 1355-1365.

Farrell, G.C., Teoh, N.C., and McCuskey, R.S. (2008). Hepatic microcirculation in fatty liver disease. Anat. Rec. 291: 684-692.

Fausto, N. (2000). Liver regeneration. J. Hepatol. 32: 19-31.

Fausto, N., Mead, J.E., Gruppuso, P.A., Castilla, A., and Jakowlew, S.B. (1991). Effects of TGF-beta $s$ in the liver: cell proliferation and fibrogenesis. Ciba Found. Symp. 157: 165-174, discussion 174-7.

Feng, A.C., Fan, H.L., Chen, T.W., and Hsieh, C.B. (2014). Hepatic hemodynamic changes during liver transplantation: a review. World J. Gastroenterol. 20: 11131-11141.

Friedman, S.L. (2008). Hepatic stellate cells: protean, multifunctional, and enigmatic cells of the liver. Physiol. Rev. 88: 125-172.

Garnier, D., Li, R., Delbos, F., Fourrier, A., Collet, C., GuguenGuillouzo, C., Chesné, C., and Nguyen, T.H. (2018). Expansion of human primary hepatocytes in vitro through their amplification as liver progenitors in a 3D organoid system. Sci. Rep. 8: 8222.

Géraud, C., Evdokimov, K., Straub, B.K., Peitsch, W.K., Demory, A., Dörflinger, Y., Schledzewski, K., Schmieder, A., Schemmer, P., Augustin, H.G., et al. (2012). Unique cell type-specific junctional complexes in vascular endothelium of human and rat liver sinusoids. PLoS One 7: e34206.

Gould, I.G., Tsai, P., Kleinfeld, D., and Linninger, A. (2017). The capillary bed offers the largest hemodynamic resistance to the cortical blood supply. J. Cereb. Blood Flow Metab. 37: 52-68.

Gracia-Sancho, J., Marrone, G., and Fernández-Iglesias, A. (2019). Hepatic microcirculation and mechanisms of portal hypertension. Nat. Rev. Gastroenterol. Hepatol. 16: 221-234.

Guglielmi, A., Ruzzenente, A., Conci, S., Valdegamberi, A., and lacono, C. (2012). How much remnant is enough in liver resection?. Dig. Surg. 29: 6-17.

Häussinger, D. and Kordes, C. (2019). Space of Disse: a stem cell niche in the liver. Biol. Chem. 401: 81-95.

Higgins, G.M. and Anderson, R.M. (1931). Experimental pathology of the liver; I. Restoration of the liver of the white rat following partial surgical removal. Arch. Pathol. 12: 186-202. 
Hoffmann, K., Nagel, A.J., Tanabe, K., Fuchs, J., Dehlke, K., Ghamarnejad, O., Lemekhova, A., and Mehrabi, A. (2020). Markers of liver regeneration-the role of growth factors and cytokines: a systematic review. BMC Surg. 20: 31.

$\mathrm{Hu}, \mathrm{C}$. and Li, L. (2015). In vitro culture of isolated primary hepatocytes and stem cell-derived hepatocyte-like cells for liver regeneration. Protein Cell 6: 562-574.

Hu, H., Gehart, H., Artegiani, B., C, Löpez-Iglesias, I, Dekkers, F., Basak, O., van Es, J., Chuva de Sousa Lopes, S.M., Begthel, H., Korving, J., et al. (2018). Long-term expansion of functional mouse and human hepatocytes as 3D organoids. Cell 175: 1591-1606 e19.

Hu, J., Srivastava, K., Wieland, M., Runge, A., Mogler, C., Besemfelder, E., Terhardt, D., Vogel, M.J., Cao, L., Korn, C., et al. (2014). Endothelial cell-derived angiopoietin-2 controls liver regeneration as a spatiotemporal rheostat. Science 343: 416-419.

ljaz, S., Yang, W., Winslet, M.C., and Seifalian, A.M. (2003). Impairment of hepatic microcirculation in fatty liver. Microcirculation 10: 447-456.

Ingber, D.E. (2003). Mechanobiology and diseases of mechanotransduction. Ann. Med. 35: 564-577.

Ito, Y., Sørensen, K.K., Bethea, N.W., Svistounov, D., McCuskey, M.K., Smedsrød, B.H., and McCuskey, R.S. (2007). Age-related changes in the hepatic microcirculation in mice. Exp. Gerontol. 42: 789-97.

Iwatsuki, S. and Starzl, T.E. (1988). Personal experience with 411 hepatic resections. Ann. Surg. 208: 421-434.

Jamieson, R.W., Zilvetti, M., Roy, D., Hughes, D., Morovat, A., Coussios, C.C., and Friend, P.J. (2011). Hepatic steatosis and normothermic perfusion-preliminary experiments in a porcine model. Transplantation 92: 289-295.

Jenne, C.N. and Kubes, P. (2013). Immune surveillance by the liver. Nat. Immunol. 14: 996-1006.

Kim, T.H., Mars, W.M., Stolz, D.B., Petersen, B.E., and Michalopoulos, G.K. (1997). Extracellular matrix remodeling at the early stages of liver regeneration in the rat. Hepatology 26: 896-904.

Knoefel, W.T., Gabor, I., Rehders, A., Alexander, A., Krausch, M., Schulte am Esch, J., Fürst, G., and Topp, S.A. (2013). In situ liver transection with portal vein ligation for rapid growth of the future liver remnant in two-stage liver resection. Br. J. Surg. 100: 388-394.

Knolle, P.A. and Wohlleber, D. (2016). Immunological functions of liver sinusoidal endothelial cells. Cell. Mol. Immunol. 13: 347-353.

Kostallari, E. and Shah, V.H. (2016). Angiocrine signaling in the hepatic sinusoids in healh and disease. Am. J. Physiol. Gastrointest. Liver Physiol. 311: G246-G251.

Kron, P., Linecker, M., Limani, P., Schlegel, A., Kambakamba, P., Lehn, J.M., Nicolau, C., Graf, R., Humar, B., and Clavien, P.A. (2016). Hypoxia-driven Hif2a coordinates mouse liver regeneration by coupling parenchymal growth to vascular expansion. Hepatology 64: 2198-2209.

Kumar, A., Sharma, P., and Sarin, S.K. (2008). Hepatic venous pressure gradient measurement: time to learn!. Indian J. Gastroenterol. 27: 74-80.

Lammert, E., Cleaver, O., and Melton, D. (2003). Role of endothelial cells in early pancreas and liver development. Mech. Dev. 120: 59-64.

Lang, S.A., Loss, M., and Schlitt, H.J. (2014). ["In-situ split" (ISS) liver resection: new aspects of technique and indication]. Zentralbl Chir 139: 212-219.
Lautt, W.W. and Greenway, C.V. (1987). Conceptual review of the hepatic vascular bed. Hepatology 7: 952-963.

Lautt, W.W., Legare, D.J., and Ezzat, W.R. (1990). Quantitation of the hepatic arterial buffer response to graded changes in portal blood flow. Gastroenterology 98: 1024-1028.

Le Couteur, D.G., Warren, A., Cogger, V.C., Smedsrød, B., Sørensen, K.K., De Cabo, R., Fraser, R., and McCuskey, R.S. (2008). Old age and the hepatic sinusoid. Anat. Rec. 291: 672-683.

Lehwald-Tywuschik, N., Vaghiri, S., Schulte Am Esch, J., Alaghmand, S., Klosterkemper, Y., Schimmöller, L., Lachenmayer, A., Ashmawy, H., Krieg, A., Topp, S.A., et al. (2020). In situ split plus portal vein ligation (ISLT)-a salvage procedure following inefficient portal vein embolization to gain adequate future liver remnant volume prior to extended liver resection. BMC Surg. 20: 63.

Li, J., Zhang, Y.P., and Kirsner, R.S. (2003). Angiogenesis in wound repair: angiogenic growth factors and the extracellular matrix. Microsc. Res. Tech. 60: 107-114.

Li, R., Oteiza, A., Sørensen, K.K., McCourt, P., Olsen, R., Smedsrød, B., and Svistounov, D. (2011). Role of liver sinusoidal endothelial cells and stabilins in elimination of oxidized low-density lipoproteins. Am. J. Physiol. Gastrointest. Liver Physiol. 300: G71-G81.

Lorenz, L., Axnick, J., Buschmann, T., Henning, C., Urner, S., Fang, S., Nurmi, H., Eichhorst, N., Holtmeier, R., Bódis, K., et al. (2018). Mechanosensing by beta1 integrin induces angiocrine signals for liver growth and survival. Nature 562: 128-132.

Maher, J.J. (1993). Cell-specific expression of hepatocyte growth factor in liver. Upregulation in sinusoidal endothelial cells after carbon tetrachloride. J. Clin. Invest. 91: 2244-2252.

Martinez-Lemus, L.A. (2012). The dynamic structure of arterioles. Basic Clin. Pharmacol. Toxicol. 110: 5-11.

Matsumoto, K., Yoshitomi, H., Rossant, J., and Zaret, K.S. (2001). Liver organogenesis promoted by endothelial cells prior to vascular function. Science 294: 559-563.

May, B.J., and Madoff, D.C. (2012). Portal vein embolization: rationale, technique, and current application. Semin. Intervent. Radiol. 29: 81-99.

McCuskey, R.S., Ito, Y., Robertson, G.R., McCuskey, M.K., Perry, M., and Farrell, G.C. (2004). Hepatic microvascular dysfunction during evolution of dietary steatohepatitis in mice. Hepatology 40: 386-393.

Melgar-Lesmes, P. and Edelman, E.R. (2015). Monocyte-endothelial cell interactions in the regulation of vascular sprouting and liver regeneration in mouse. J. Hepatol. 63: 917-925.

Mergental, H., Laing, R.W., Kirkham, A.J., Perera, M., Boteon, Y.L., Attard, J., Barton, D., Curbishley, S., Wilkhu, M., Neil, D.A.H., et al (2020). Transplantation of discarded livers following viability testing with normothermic machine perfusion. Nat. Commun. 11: 2939.

Michalopoulos, G.K. (2007). Liver regeneration. J. Cell. Physiol. 213: 286-300.

Michalopoulos, G.K. (2010). Liver regeneration after partial hepatectomy: critical analysis of mechanistic dilemmas. Am. J. Pathol. 176: 2-13.

Michalopoulos, G.K. and DeFrances, M.C. (1997). Liver regeneration. Science 276: 60-66.

Mitchell, C. and Willenbring, H. (2008). A reproducible and welltolerated method for $2 / 3$ partial hepatectomy in mice. Nat. Protoc. 3: 1167-1170.

Mohammed, F.F., Pennington, C.J., Kassiri, Z., Rubin, J.S., Soloway, P.D., Ruther, U., Edwards, D.R., and Khokha, R. (2005). 
Metalloproteinase inhibitor TIMP-1 affects hepatocyte cell cycle via HGF activation in murine liver regeneration. Hepatology 41: 857-867.

Morsiani, E., Aleotti, A., and Ricci, D. (1998). Haemodynamic and ultrastructural observations on the rat liver after two-thirds partial hepatectomy. J. Anat. 192: 507-515.

Nasralla, D., Coussios, C.C., Mergental, H., Akhtar, M.Z., Butler, A.J., Ceresa, C.D.L., Chiocchia, V., Dutton, S.J., García-Valdecasas, J.C., Heaton, N., et al. (2018). A randomized trial of normothermic preservation in liver transplantation. Nature 557: 50-56.

Naugler, W.E., Tarlow, B.D., Fedorov, L.M., Taylor, M., Pelz, C., Li, B., Darnell, J., and Grompe, M. (2015). Fibroblast growth factor signaling controls liver size in mice with humanized livers. Gastroenterology 149: 728-40 e15.

Granger, D. N., Holm, L., and Kvietys, P. (2015). The gastrointestinal circulation: physiology and pathophysiology. Compr. Physiol. 5: 1541-1583.

Pack, G.T., Islami, A.H., Hubbard, J.C., and Brasfield, R.D. (1962). Regeneration of human liver after major hepatectomy. Surgery 52: 617-623.

Paranjpe, S., Bowen, W.C., Mars, W.M., Orr, A., Haynes, M.M., DeFrances, M.C., Liu, S., Tseng, G.C., Tsagianni, A., and Michalopoulos, G.K. (2016). Combined systemic elimination of MET and epidermal growth factor receptor signaling completely abolishes liver regeneration and leads to liver decompensation. Hepatology 64: 1711-1724.

Poisson, J., Lemoinne, S., Boulanger, C., Durand, F., Moreau, R., Valla, D., and Rautou, P.E. (2017). Liver sinusoidal endothelial cells: physiology and role in liver diseases. J. Hepatol. 66: 212-227.

Rafii, S., Butler, J.M., and Ding, B.S. (2016). Angiocrine functions of organ-specific endothelial cells. Nature 529: 316-325.

Rocha, F.G. (2012). Liver blood flow: physiology, measurement, and clinical relevance. In: Jarnagin, W.R., and Blumgart, L.H. (Eds.). Blumgart's Surgery of the liver, pancreas and biliary tract, 5 th ed. Philadelphia, USA: W.B. Saunders, pp. 74-86.e5.

Rohn, F., Kordes, C., Buschmann, T., Reichert, D., Wammers, M., Poschmann, G., Stühler, K., Benk, A.S., Geiger, F., Spatz, J.P., et al (2020). Impaired integrin alpha5/beta1 -mediated hepatocyte growth factor release by stellate cells of the aged liver. Aging Cell 19: e13131.

Runge, D., Runge, D.M., Jäger, D., Lubecki, K.A., Beer Stolz, D., Karathanasis, S., Kietzmann, T., Strom, S.C., Jungermann, K., Fleig, W.E., et al (2000). Serum-free, long-term cultures of human hepatocytes: maintenance of cell morphology, transcription factors, and liver-specific functions. Biochem. Biophys. Res. Commun. 269: 46-53.

Russell, W.E., Coffey, R.J., Jr., Ouellette, A.J., and Moses, H.L. (1988). Type beta transforming growth factor reversibly inhibits the early proliferative response to partial hepatectomy in the rat. Proc. Natl. Acad. Sci. U.S.A. 85: 5126-5130.

Sanz, N., Díez-Fernández, C., Alvarez, A.M., Fernández-Simón, L., and Cascales, M. (1999). Age-related changes on parameters of experimentally-induced liver injury and regeneration. Toxicol. Appl. Pharmacol. 154: 40-49.

Sato, N., Eguchi, H., Inoue, A., Matsumura, T., Kawano, S., and Kamada, T. (1986). Hepatic microcirculation in Zucker fatty rats. Adv. Exp. Med. Biol. 200: 477-483.

Sawitza, I., Kordes, C., Reister, S., and Häussinger, D. (2009). The niche of stellate cells within rat liver. Hepatology 50: 1617-1624.
Schlayer, H.J., Laaff, H., Peters, T., Woort-Menker, M., Estler, H.C., Karck, U., Schaefer, H.E., and Decker, K. (1988). Involvement of tumor necrosis factor in endotoxin-triggered neutrophil adherence to sinusoidal endothelial cells of mouse liver and its modulation in acute phase. J. Hepatol. 7: 239-249.

Schlitt, H.J., Hackl, C., and Lang, S.A. (2017). 'In-situ-split' liver resection/ALPPS - historical development and current practice. Vis. Media 33: 408-412.

Schmidt, C., Bladt, F., Goedecke, S., Brinkmann, V., Zschiesche, W., Sharpe, M., Gherardi, E., and Birchmeler, C. (1995). Scatter factor/hepatocyte growth factor is essential for liver development. Nature 373: 699-702.

Schmucker, D.L., and Sanchez, H. (2011). Liver regeneration and aging: a current perspective. Curr Gerontol Geriatr Res 2011: 526379.

Schnitzbauer, A.A., Lang, S.A., Goessmann, H., Nadalin, S., Baumgart, J., Farkas, S.A., Fichtner-Feigl, S., Lorf, T., Goralcyk, A., Hörbelt, R., et al. (2012). Right portal vein ligation combined with in situ splitting induces rapid left lateral liver lobe hypertrophy enabling 2-staged extended right hepatic resection in small-for-size settings. Ann. Surg. 255: 405-414.

Seifalian, A.M., Chidambaram, V., Rolles, K., and Davidson, B.R. (1998). In vivo demonstration of impaired microcirculation in steatotic human liver grafts. Liver Transpl. Surg. 4: 71-77.

Seifalian, A.M., Piasecki, C., Agarwal, A., and Davidson, B.R. (1999). The effect of graded steatosis on flow in the hepatic parenchymal microcirculation. Transplantation 68: 780-784.

Selzner, M. and Clavien, P.A. (2000). Failure of regeneration of the steatotic rat liver: disruption at two different levels in the regeneration pathway. Hepatology 31: 35-42.

Shimizu, H., Miyazaki, M., Wakabayashi, Y., Mitsuhashi, N., Kato, A., Ito, H., Nakagawa, K., Yoshidome, H., Kataoka, M., and Nakajima, N. (2001). Vascular endothelial growth factor secreted by replicating hepatocytes induces sinusoidal endothelial cell proliferation during regeneration after partial hepatectomy in rats. J. Hepatol. 34: 683-689.

Shindoh, J., Vauthey, J.N., Zimmitti, G., Curley, S.A., Huang, S.Y., Mahvash, A., Gupta, S., Wallace, M.J., and Aloia, T.A. (2013). Analysis of the efficacy of portal vein embolization for patients with extensive liver malignancy and very low future liver remnant volume, including a comparison with the associating liver partition with portal vein ligation for staged hepatectomy approach. J. Am. Coll. Surg. 217: 126-133, discussion 133-4.

Smyrniotis, V., Kostopanagiotou, G., Kondi, A., Gamaletsos, E., Theodoraki, K., Kehagias, D., Mystakidou, K., and Contis, J. (2002). Hemodynamic interaction between portal vein and hepatic artery flow in small-for-size split liver transplantation. Transpl. Int. 15: 355-360.

Sørensen, K.K., McCourt, P., Berg, T., Crossley, C., Le Couteur, D., Wake, K., and Smedsrød, B. (2012). The scavenger endothelial cell: a new player in homeostasis and immunity. Am. J. Physiol. Regul. Integr. Comp. Physiol. 303: R1217-R1230.

Sørensen, K.K., Simon-Santamaria, J., McCuskey, R.S., and Smedsrød, B. (2015). Liver sinusoidal endothelial cells. Compr. Physiol. 5: 1751-1774.

Soydemir, S., Comella, O., Abdelmottaleb, D., and Pritchett, J. (2020). Does mechanocrine signaling by liver sinusoidal endothelial cells offer new opportunities for the development of antifibrotics?. Front. Med. 6: 312. 
Speicher, T., Siegenthaler, B., Bogorad, R.L., Ruppert, R., Petzold, T., Padrissa-Altes, S., Bachofner, M., Anderson, D.G., Koteliansky, V., Fässler, R., et al. (2014). Knockdown and knockout of $\beta 1$-integrin in hepatocytes impairs liver regeneration through inhibition of growth factor signalling. Nat. Commun. 5: 3862.

Tammela, T., Zarkada, G., Wallgard, E., Murtomäki, A., Suchting, S., Wirzenius, M., Waltari, M., Hellström, M., Schomber, T., Peltonen, R., et al. (2008). Blocking VEGFR-3 suppresses angiogenic sprouting and vascular network formation. Nature 454: 656-660.

Taub, R. (2004). Liver regeneration: from myth to mechanism. Nat. Rev. Mol. Cell Biol. 5: 836-847.

Timchenko, N.A. (2009). Aging and liver regeneration. Trends Endocrinol. Metab. 20: 171-176.

Urner, S., Kelly-Goss, M., Peirce, S.M., and Lammert, E. (2018). Mechanotransduction in blood and lymphatic vascular development and disease. Adv. Pharmacol. 81: 155-208.

Valdecantos, M.P., Pardo, V., Ruiz, L., Castro-Sánchez, L., Lanzón, B., Fernández-Millán, E., García-Monzón, C., Arroba, A.I., GonzálezRodríguez, A., Escrivá, F., et al. (2017). A novel glucagon-like peptide 1 /glucagon receptor dual agonist improves steatohepatitis and liver regeneration in mice. Hepatology 65: 950-968.

Wang, L., Wang, X., Xie, G., Wang, L., Hill, C.K., and DeLeve, L.D. (2012). Liver sinusoidal endothelial cell progenitor cells promote liver regeneration in rats. J. Clin. Invest. 122: 1567-1573.

Wirz, W., Antoine, M., Tag, C.G., Gressner, A.M., Korff, T., Hellerbrand, C., and Kiefer, P. (2008). Hepatic stellate cells display a functional vascular smooth muscle cell phenotype in a threedimensional co-culture model with endothelial cells. Differentiation 76: 784-794.
Wynne, H.A., Cope, L.H., Mutch, E., Rawlins, M.D., Woodhouse, K.W., and James, O.F. (1989). The effect of age upon liver volume and apparent liver blood flow in healthy man. Hepatology 9 : 297-301.

Yamada, Y., Kirillova, I., Peschon, J.J., and Fausto, N. (1997). Initiation of liver growth by tumor necrosis factor: deficient liver regeneration in mice lacking type I tumor necrosis factor receptor. Proc. Natl. Acad. Sci. U.S.A. 94: 1441-1416.

Yang, S.Q., Lin, H.Z., Mandal, A.K., Huang, J., and Diehl, A.M. (2001). Disrupted signaling and inhibited regeneration in obese mice with fatty livers: implications for nonalcoholic fatty liver disease pathophysiology. Hepatology 34: 694-706.

Zhang, X.J., Olsavszky, V., Yin, Y., Wang, B., Engleitner, T., Öllinger, R., Schledzewski, K., Koch, P.S., Rad, R., Schmid, R.M., et al. (2020). Angiocrine hepatocyte growth factor signaling controls physiological organ and body size and dynamic hepatocyte proliferation to prevent liver damage during regeneration. Am. J. Pathol. 190: 358-371.

Zhu, C., Ikemoto, T., Utsunomiya, T., Yamada, S., Morine, Y., Imura, S., Arakawa, Y., Takasu, C., Ishikawa, D., and Shimada, M. (2014). Senescence-related genes possibly responsible for poor liver regeneration after hepatectomy in elderly patients. J. Gastroenterol. Hepatol. 29: 1102-1108.

Zimmers, T.A., Jin, X., Zhang, Z., Jiang, Y., and Koniaris, L.G. (2017). Epidermal growth factor receptor restoration rescues the fatty liver regeneration in mice. Am. J. Physiol. Endocrinol. Metab. 313: E440-E449.

Zoli, M., Magalotti, D., Bianchi, G., Gueli, C., Orlandini, C., Grimaldi, M., and Marchesini, G. (1999). Total and functional hepatic blood flow decrease in parallel with ageing. Age Ageing 28: 29-33. 